\title{
The referral centers for the diagnosis and treatment of hypertension in adolescents
}

\author{
Giovanni Cerasola*, Giuseppe Mulè, Santina Cottone \\ From 71st Congress of the Italian Society of Pediatrics. Joint National Meeting SIP, SIMGePeD, Study Group \\ on Pediatric Ultrasound, SUP Study Group on Hypertension \\ Rome, Italy. 4-6 June 2015
}

Primary hypertension in adolescence was felt to be quite rare. However, the worldwide childhood obesity epidemic has had a profound impact on the frequency of high blood pressure (BP) with the result that primary hypertension should now be viewed as one of the most common health conditions in the young (estimated prevalence $1-5 \%$ ).

Therefore, current guidelines recommend that all children and adolescents seen in a medical setting should have their BP measured. The availability of BP tables with normal BP percentiles for age, sex and height has improved BP values classification.

Studies conducted at referral clinics for evaluation of hypertension have indicated that as many as 30 to $40 \%$ of adolescents may actually have in a clinical setting white-coat hypertension. This may lead to a misdiagnosis of "true" hypertension in a considerable number of cases. The usefulness of out-of-office BP evaluation using ambulatory or home monitoring is well established. These measurements allow the detection of the white-coat and masked hypertension, the opposite of white-coat hypertension, and are more closely associated with organ damage and cardiovascular risk than office measurements. A thorough familial and personal history is of primary importance as well as the physical examination that should be focused on the search for signs suggestive for an underlying cause and/or for the severity of hypertension.

Following investigations must be tailored to the child's age, anamnesis and clinical examination and to the severity of BP elevation, in order to investigate not only the possible cause of hypertension, but also associated
Table 1. What is required at the referral centers in the management of hypertension in adolescence

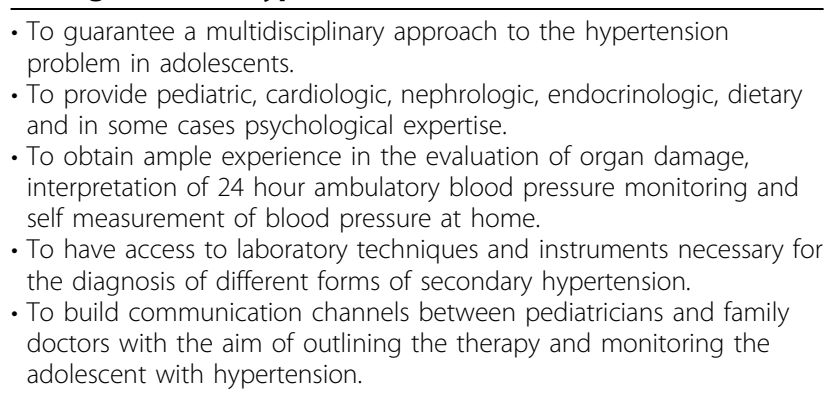

diseases and target organs damage. Therapeutic approach should firstly include non-pharmacological measures, and the use of medications when indicated.

A key role in the management of the adolescents with hypertension may be attributed to the hypertension referral centers (table 1).

Published: 30 September 2015

doi:10.1186/1824-7288-41-S2-A14

Cite this article as: Cerasola et al:: The referral centers for the diagnosis and treatment of hypertension in adolescents. Italian Journal of Pediatrics 2015 41(Suppl 2):A14.

\footnotetext{
* Correspondence: giovanni.cerasola@unipa.it

European Society of Hypertension Excellence Centre of Palermo.

Dipartimento Biomedico di Medicina Interna e Specialistica. Università di

Palermo, Italy
} 